\title{
Improving reproductive efficiency of chickpea by foliar application of zinc
}

\author{
Girish Chandra Pathak¹, Bhavana Gupta ${ }^{1}$, Nalini Pandey ${ }^{1 *}$ \\ 1Plant Nutrition and Stress Physiology Laboratory, Department of Botany, University of Lucknow, Lucknow \\ 226007, India.
}

*Corresponding author: nalini_pandey@rediffmail.com

Received: 29 May 2012; Accepted: 03 September 2012

\begin{abstract}
Zinc deficiency is not only the cause of low productivity of crops, but it also results in low zinc content in seeds, which leads to poor dietary zinc intake. To study the effect of zinc foliar application on improving plant yield and seed zinc content for human consumption, chickpea plants were raised in refined sand culture with deficient $(0.2 \mu \mathrm{M})$ and sufficient $(1 \mu \mathrm{M})$ supply of zinc under glass-house conditions. Prior to initiation of the reproductive phase, zinc was applied as $0.1 \% \mathrm{ZnSO}_{4}$ foliar spray to both zinc sufficient and deficient plants. The plants exposed to different zinc treatments were studied for pollen and stigma structure and their involvement in fertilization and seed yield. Zinc deficiency induces flower abortion, pollen, and ovule infertility leading to low seed set and ultimately its yield. Foliar application of $\mathrm{ZnSO}_{4}$ to zinc deficient plants at the time of initiation of flowering partially reverses the adverse effect of zinc deficiency on pollen-stigma morphology, pollen fertility, and greatly enhanced seed yield of plants. Zinc foliar application improved not only the boldness and vigor of seeds in zincdeficient plants, but also the seed zinc content in zinc-deficient seeds as well as the sufficient ones.
\end{abstract}

Keywords: Cicer arietinum (L.), foliar application, reproductive development, zinc deficiency.

\section{INTRODUCTION}

Introduction of high yielding varieties and use of high input fertilizers have caused depletion of micronutrients, mainly of zinc (Zn) on the soil. Approximately $60 \%$ of the world soil is considered inadequate for crop production, due to mineral stress caused by the deficiency, unavailability, or toxicity of some essential nutritive elements. Mineral fertilization is one of the most important factors for improving yield, and the crop yield and its quality can be improved by adequate soil and crop management practices. Zn deficiency is one of the most common ones prevalent in the world (Alloway, 2004). In Indian soil, it is a critical nutrient deficiency since these $\mathrm{Zn}$ deficient $(\mathrm{ZnD})$ soils are under intensive cultivation of food crops, chiefly cereals and legumes. Not only the yield but also the Zn content in the seeds is highly reduced due to poor fertilization practices. This has resulted in increasing incidences of malnutrition and health problems, especially in children (Cakmak, 2010). Proper plant nutrition including that of $\mathrm{Zn}$ has a key role to play in alleviating the hunger, nutrition disorders, and malnutrition that exist in many of the developing countries including India. Since legumes are the major source of protein for the vegetarian population of the country, it is important that they are intensively fortified with $\mathrm{Zn}$ to overcome the health problem. Chickpea is an important legume grown in India and is an important source of dietary protein and mineral nutrient. However, productivity of chickpea like other legumes has been low due to the widespread Zn deficiency.

$\mathrm{Zn}$ is one of the essential plant nutrients that functions in diverse metabolic, regulatory, and developmental processes (Broadly et al., 2007). Apart from being a constituent of Zn-metalloenzymes, Zn functions as a 
constituent of several regulatory proteins like the $Z n$ finger ones that interact with DNA and control gene expression (Liu et al., 2005). Zn plays an important role in plantreproductive development for initiation of flowering, floral development, male and female gametogenesis, fertilization, and seed development. Even under marginal Zn deficiency condition, the development of anthers in wheat is severely retarded (Sharma et al., 1990). Pandey et al. (1995) reported that Zn deficiency induced a change in exine morphology and reduced pollen viability. Zn deficiency has also been shown to change stigmatic size, morphology, and exudations, inhibiting pollen-stigma interaction (Pandey et al., 2006; 2009b). It was recently documented that $\mathrm{Zn}$ foliar application is a simple way for making quick correction of plant nutritional status, as reported for maize (Grzebisz et al., 2008) and green gram (Pathak and Pandey, 2010). Most researches on Zn foliar application focused on alleviating its deficiency, particularly on wheat and maize cultivated in semiarid regions of the world (Cakmak, 2008; Potaezycki and Grzebisz, 2009). In the present study we explored the effect of $\mathrm{Zn}$ foliar application on the reproductive development of chickpea with a view to assess its effect on pollen stigma interaction and on the $\mathrm{Zn}$ content in seeds for improved dietary intake by humans.

\section{MATERIALS AND METHODS}

Plant culture: Chickpea (Cicer arietinum L. var. BG1053) seeds were raised in purified silica sand in $5 \mathrm{~L}$ polyethylene pots provided with a central drainage hole and covered with an inverted watch glass under the rim (Pandey et al., 2009a). The plants were grown in nutrient solution containing: $4 \mathrm{mM} \mathrm{Ca}\left(\mathrm{NO}_{3}\right)_{2}, 4 \mathrm{mM} \mathrm{KNO}_{3}, 2 \mathrm{mM}$ $\mathrm{MgSO}_{4}, 1.33 \mathrm{mM} \mathrm{NaH}_{2} \mathrm{PO}_{4}, 0.33 \mathrm{mM} \mathrm{H}_{3} \mathrm{BO}_{3}, 0.1 \mathrm{mM}$ Fe-EDTA, $10 \mu \mathrm{M} \mathrm{MnSO}_{4}, 1 \mu \mathrm{M} \mathrm{CuSO}_{4}, 0.2 \mu \mathrm{M} \mathrm{Na}_{2} \mathrm{MoO}_{4}$, $0.1 \mathrm{mM} \mathrm{NaCl}, 0.1 \mu \mathrm{M} \mathrm{CoSO}_{4}$, and $0.1 \mu \mathrm{M} \mathrm{NiSO}_{4}$. During the course of the experiment, the average day length was 10.45 hours with maximum light intensity, photosynthetic photon flux density (PPFD) at 12:00 am ranging between 600 and $900 \mu \mathrm{mol} \mathrm{m}{ }^{-2} \mathrm{~s}^{-1}$. The temperature during 24 hours ranged between 18.5 and $22^{\circ} \mathrm{C}$ (maximum) and 6.5 and $15.5^{\circ} \mathrm{C}$ (minimum). The humidity at 9:30 am was from 85 to $95 \%$.

$\mathrm{Zn}$ was supplied in the form of $\mathrm{ZnSO}_{4}$ as $0.2 \mu \mathrm{M}$ (deficient) and $1 \mu \mathrm{M}$ (sufficient). One set of each $\mathrm{ZnD}$ and $\mathrm{Zn}$ sufficient $(\mathrm{ZnS})$ plants were given foliar spray of $0.1 \% \mathrm{ZnSO}_{4}$ at the initiation of flowering (at 55 days), and these treatments were referred as deficient foliar (ZnDF) and sufficient foliar (ZnSF), respectively. Plants receiving the four treatments - deficient $(\mathrm{ZnD})$, sufficient $(\mathrm{ZnS})$, deficient foliar (ZnDF), and sufficient foliar (ZnSF) - were grown to maturity and quantified for different parameters.

Dry matter and seed yields: Dry matter yield was determined by oven-drying plants part (leaves, stem, and roots) at $70^{\circ} \mathrm{C}$ after 62 days of $\mathrm{Zn}$ treatment and seed yield at harvest.

Tissue zinc concentration: $\mathrm{Zn}$ in leaves and seed was determined by atomic absorption spectrophotometer (Perkin Elmer A Analyst 300, The Netherlands) after wet acid digestion $\left(\mathrm{HNO}_{3}: \mathrm{HClO}_{4} ; 10: 1\right)$ of oven dried $\left(80^{\circ} \mathrm{C}\right)$ plant material.

Scanning and light microscopy: To observe the stigmatic secretion and surface details of stigma and pollen grains, both fresh and fixed samples were examined. Fresh flowers were collected between 7:00 am to $9: 00 \mathrm{pm}$, and fixed in $1.5 \%$ glutaraldehyde and $0.05 \mathrm{M}$ phosphate buffer at $\mathrm{pH}=7.2$ for 14 hours with two-hour-post fixation in 1\% osmium tetraoxide. For studying the surface ornamentations of the pollen grains and stigma, they were dehydrated through graded ethanol-isoamyl series, dried in critical point dryer (CPD), mounted on stubs, and coated with gold palladium (Erdtman, 1986). Specimens were observed and photographed using a LEO 430 scanning electron microscope (LEO Electron Microscopy Ltd., Cambridge, UK). Light microscopic examination of the pollen grains and anthers was done under a Nikon E-400 microscope (Tokyo, Japan). Sizes of anther and pollen grains were measured after mounting the preparation in glycerin jelly. The size of anthers was measured in five sets and that of pollen grains in five sets of 20 pollen grains for each treatment in triplicate.

Pollen viability: Pollen germination was determined by germinating the pollen grains in a culture medium containing $10 \%$ sucrose, $0.01 \%$ boric acid, $0.03 \%$ calcium nitrate, $0.02 \%$ magnesium sulphate, and $0.01 \%$ potassium nitrate by the hanging-drop method in a cavity slide (Brewbaker and Kwack, 1963). Scoring was based on five sets of 20 pollen grains in triplicate for each treatment under the microscope. The pollen grains having pollen tubes longer than the pollen diameter were taken as viable.

Cytochemical localization of enzymes on stigma surface: For localization of enzyme acid phosphatase (EC 3.1.3.2) and esterase (EC 3.1.1.6) on stigma surface (Shivana and Rangaswamy, 1992), stigmas from 10 to 20 flowers were gently excised without injuring the stigma and style. The stigmas were placed in a cavity slide so 
that the styles did not dip into the solution. They were also incubated in the reaction solution as mentioned below for 10 to 20 minutes at 25 to $35^{\circ} \mathrm{C}$ in a humid chamber.

For localization of acid phosphatase the stigmas were placed in a reaction mixture including $\alpha$-naphthyl phosphate as the substrate, fast garnet GBC as the coupling agent in $0.1 \mathrm{M}$ acetate buffer $(\mathrm{pH}=4.0)$, and $10 \% \mathrm{MgCl}_{2}$. Staining for localization of esterase was performed in a freshly prepared solution of $\alpha$-naphthyl acetate (Sigma, USA) in a $0.15 \mathrm{M}$ phosphate buffer, $10 \%$ sucrose, and $25 \mathrm{mg}$ fast blue B salt (Sigma, USA). For control, $\alpha$-naphthyl acetate was excluded from the reaction mixture.

Staining for localization of peroxidase (EC.1.11.1.7) on stigma was done in a freshly prepared solution of $0.5 \%$ paraphenylenediamine and $0.5 \% \mathrm{H}_{2} \mathrm{O}_{2}$, and it was washed thoroughly in phosphate buffer (Raa, 1973).

Enzyme assay: Assay of peroxidase and acid phosphatase was carried out in the crude extracts of pollen grains using methods described by Sharma et al. (1987). Peroxidase activity was determined in a reaction mixture containing $0.05 \mathrm{~mol} / \mathrm{L}$ phosphate buffer $(\mathrm{pH}=6.0)$, $0.01 \% \mathrm{H}_{2} \mathrm{O}_{2}$, and $5 \mathrm{mg} p$-phenylenediamine- $\mathrm{HCl}$. The reaction was stopped by adding $4 \mathrm{~N} \mathrm{H}_{2} \mathrm{SO}_{4}$. A change in optical density (OD) was read at $485 \mathrm{~nm}$ in UltravioletVisible spectrophotometer - UV-VIS (Perkin Elmer,
Lambda Bio 20, The Netherlands). The assay system for acid phosphatase contained $0.05 \mathrm{~mol} \mathrm{~L}^{-1}$ acetate buffer $(\mathrm{pH}=5.0)$ and $0.01 \mathrm{~mol} \mathrm{~L}^{-1}$ sodium B-glycerophosphate. The reaction was stopped by adding $10 \%$ trichloroacetic acid (TCA). The enzyme activity was expressed in terms of $\mu \mathrm{g}$ Pi phosphorus liberated.

Poly acrylamide gel electrophoresis separation: For studying the effect of $\mathrm{Zn}$ treatments on the expression of peroxidase acid phosphatase and esterase isoenzymes in the pollen grains and pollen receptive area of stigmas, the extracts of pollen grains and stigma exudates of $\mathrm{ZnS}$ and deficient plants were separated on $10 \%$ native PAGE and visualized by the method of Brewbaker et al. (1968). The stigma exudates were collected from 20 stigma heads in $10 \mu \mathrm{L}$ of $0.15 \mathrm{~mol} \mathrm{~L}^{-1}$ phosphate buffer $(\mathrm{pH}=5.0)$. The gels were stained for acid phosphatase in a solution containing $0.1 \mathrm{M} \mathrm{MgCl}_{2} 1 \% \alpha$-naphthyl acid phosphate, and fast garnet GBC salt in $0.2 \mathrm{M}$ acetate buffer, $\mathrm{pH}=5.0$, and for esterase in a solution containing $1 \% \alpha$-naphthyl acetate and fast blue RR in $0.3 \mathrm{M}$ phosphate buffer $(\mathrm{pH}=7.2)$. All stains for the reaction mixture were obtained from Sigma Chemical Co. USA.

Statistical analysis: Each treatment had three replicates of two plants each, and experimental data were statistically analyzed using the analysis of variance (ANOVA). The mean values and the least significant differences (LSD at $p \leq 0.05$ ) are presented in Table 1.

Table 1. Effect of zinc foliar application on flower number, anther and pollen sizes, pollen viability, activity of acid phosphatase and peroxidase in pollen grain extracts, pod and seed weight and viability of seeds of chickpea (Cicer arietinum $\mathrm{L}$.). The mean values \pm Standard error $(n=3)$ indicate significant differences compared to the Control at $p \leq 0.05$.

\begin{tabular}{|c|c|c|c|c|c|}
\hline \multirow{2}{*}{ Parameters } & \multicolumn{4}{|c|}{ Zn treatments } & \multirow{2}{*}{ 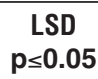 } \\
\hline & $\mathrm{ZnD}$ & ZnDF & ZnS & ZnSF & \\
\hline Dry matter yield (g plant ${ }^{-1}$ ) & $4.98 \pm 0.26$ & $7.60 \pm 0.49$ & $11.55 \pm 0.64$ & $12.32 \pm 0.58$ & 0.90 \\
\hline Leaf tissue $\mathrm{Zn}$ ( $\mu \mathrm{g} \mathrm{g} \mathrm{g}^{-1}$ dry weight) & $15.56 \pm 0.64$ & $25.22 \pm 0.58$ & $38.86 \pm 0.76$ & $55.24 \pm 0.86$ & 1.53 \\
\hline Number of flower plant ${ }^{-1}$ & $16.0 \pm 0.95$ & $18.0 \pm 0.89$ & $23.0 \pm 0.83$ & $25.0 \pm 1.05$ & 2.62 \\
\hline Flower size $(\mathrm{mm})$ & $6.0 \pm 0.01$ & $8.3 \pm 0.02$ & $12 \pm 0.04$ & $12 \pm 0.03$ & 0.01 \\
\hline Anther size $(\mu \mathrm{m})$ & $360.0 \pm 12.05$ & $389.0 \pm 10.65$ & $450.0 \pm 9.95$ & $465.0 \pm 11.95$ & 25.45 \\
\hline Pollen size $(\mu \mathrm{m})$ & $52.5 \pm 2.94$ & $59.2 \pm 1.90$ & $70.4 \pm 2.45$ & $72.3 \pm 2.85$ & 3.56 \\
\hline Pollen viability (\% germination) & $40.0 \pm 1.25$ & $65.0 \pm 1.43$ & $79.0 \pm 1.78$ & $88.0 \pm 4.93$ & 4.46 \\
\hline Acid phosphatase ( $\mu \mathrm{g}$ Pi liberated $\mathrm{mg}^{-1}$ protein) & $121.0 \pm 10.02$ & $111.0 \pm 14.30$ & $89.0 \pm 8.39$ & $87.0 \pm 7.34$ & 6.6 \\
\hline Peroxidase (unit $\mathrm{mg}^{-1}$ protein) & $60.0 \pm 3.15$ & $58.0 \pm 3.86$ & $38.0 \pm 2.90$ & $37.0 \pm 1.69$ & 3.04 \\
\hline Esterase (unit mg ${ }^{-1}$ protein) & $20.15 \pm 0.92$ & $37.67 \pm 1.22$ & $50.31 \pm 2.56$ & $52.64 \pm 3.10$ & 2.92 \\
\hline Number of pods plant ${ }^{-1}$ & $12.0 \pm 0.35$ & $17.0 \pm 0.49$ & $20.0 \pm 0.68$ & $21.0 \pm 0.92$ & 1.42 \\
\hline Dry weight of pod g plant ${ }^{-1}$ & $3.11 \pm 0.34$ & $5.06 \pm 0.25$ & $6.89 \pm 0.46$ & $7.05 \pm 0.75$ & 0.48 \\
\hline Number of seeds plant ${ }^{-1}$ & $14.0 \pm 0.58$ & $21.0 \pm 0.98$ & $28.0 \pm 1.89$ & $29.0 \pm 1.93$ & 1.87 \\
\hline Seed size (mm) & $0.31 \pm 0.003$ & $0.39 \pm 0.004$ & $0.56 \pm 0.001$ & $0.59 \pm 0.006$ & 0.001 \\
\hline Weight of seeds g plant ${ }^{-1}$ & $1.98 \pm 0.23$ & $3.89 \pm 0.34$ & $5.58 \pm 0.43$ & $6.05 \pm 0.37$ & 0.65 \\
\hline Seed viability (\% germination) & $45.0 \pm 2.25$ & $74.0 \pm 1.90$ & $86.0 \pm 2.91$ & $90.0 \pm 3.35$ & 3.69 \\
\hline Seed Zn ( $\mu \mathrm{g} \mathrm{g}^{-1}$ dry weight) & $10.56 \pm 0.49$ & $35.34 \pm 1.42$ & $48.82 \pm 1.96$ & $70.30 \pm 2.43$ & 3.56 \\
\hline
\end{tabular}

ZnD: Zn deficient; ZnDF: Zn deficient plants given foliar Zn; ZnS: Zn sufficient; ZnSF: Zn sufficient plants given foliar Zn; LSD: least significant difference. 


\section{RESULTS}

Zn deficiency symptoms were first observed after 25 days of nutrient supply, which later became more severe. The difference in growth was observed throughout growth period in $\mathrm{ZnS}$ and $\mathrm{ZnD}$ plants. Zn deficiency $(0.2 \mu \mathrm{M} \mathrm{Zn})$ suppressed growth, height, branching, and leaf size of plants. It also caused reduction of internodes due to which the terminal leaves appeared clustered. The leaves developed marginal chlorosis of leaflets leading to necrosis. Zn deficiency decreased the dry matter yield, which was increased by $\mathrm{Zn}$ fertilization (Table 1). There was an increase in $\mathrm{Zn}$ concentration in the leaves and seeds after $\mathrm{Zn}$ foliar application to $\mathrm{ZnD}$ as well as $\mathrm{ZnS}$ plants. $\mathrm{Zn}$ concentration increased from $10 \mu \mathrm{g} \mathrm{g} \mathrm{g}^{-1}$ dry weight in $\mathrm{ZnD}$ seeds to $35 \mathrm{\mu g} \mathrm{g}^{-1}$ dry weight in $\mathrm{ZnD}$ foliar seeds (Table 1).

Flowering was delayed by almost four to five days in plants that were grown with low Zn supply $(0.2 \mu \mathrm{M}$ $\mathrm{Zn})$, and most of the flowers failed to produce pods and seeds. In comparisons with the plants given low Zn supply, the number and weight of pods and seeds formed was high in plants given sufficient Zn supply. Zn deficiency not only affected the seed setting, but also their viability. $Z n$ concentration was also increased in seeds of ZnD plants by Zn foliar application (Table 1).

The plants grown with low Zn supply showed decrease in anther size compared to ZnS plants (Table 1). As compared to the plants grown with sufficient $\mathrm{Zn}, \mathrm{ZnD}$ plants exhibited a marked decrease in size and viability of the pollen grains (Table 1; Figures $1 \mathrm{~A}, \mathrm{~B})$. The $\mathrm{ZnD}$ pollen grains were smaller and nonviable as they did not stain in acetocarmine (Figure $1 \mathrm{~A}$ ). The pollen grains of $\mathrm{ZnD}$ plants (Figure $1 \mathrm{C}$ ) also showed poor in vitro germination, failing to germinate and/or poorly developed and sometimes burst pollen tubes, compared to the ZnS plants (Figure 1D). Zn foliar application significantly improved the size of anther and pollen grains, and germinability of pollen grains in $\mathrm{ZnD}$, but the increase was not as much as in the ZnS plants (Table 1). The ZnS pollen grain germinability was also improved by foliar $\mathrm{Zn}$, however it was not significant (Table 1). Scanning electron microscopy (SEM) studies on pollen grains showed the morphological changes in pollen shape and size. The $\mathrm{ZnD}$ pollens (Figure $1 \mathrm{E}$ ) were smaller and had heavy wax depositions in comparison to the ZnS ones (Figure $1 F)$. SEM of stigmas from flowers of $Z n D$ plants showed a decrease in the pollen receptive area and a persistent cuticle over the stigmatic surface (Figure 1G). The stigmatic head of ZnS plants had a ruptured stigmatic cuticle and heavy exudation (Figure $1 \mathrm{H}$ ).

Zn deficiency increased the activity of acid phosphatase and peroxidase (POD) in pollen grains in comparison to ZnS and ZnSF plants (Table 1). Cytochemical localization of peroxidase (Figures 2A, B) and acid phosphatase (Figures 2D, E) on the stigma surface showed an increase in both enzymes under $\mathrm{Zn}$ deficiency (Figures $2 \mathrm{~A}$ and $\mathrm{D}$ ). The expression of acid phosphatase (Figure 2C) and peroxidase (Figure 2F) in native PAGE in stigma exudates and pollen grain extracts of $\mathrm{ZnD}$ plants was similarly expressed. Five bands of peroxidase (POD) were observed, of which bands 3 and 5 in stigma exudates of $\mathrm{ZnS}$ and ZnSF (Figure 2C) were very faint. Four isoforms of acid phosphatase were expressed in stigma exudates and two in pollen extracts, and all of them, mainly band 1 , were expressed to a greater extent in response to $\mathrm{Zn}$ deficiency. Cytochemical localization of esterase on the stigma presented lower activity of esterase in $\mathrm{ZnD}$ plants (Figure 2G) as compared to the $\mathrm{ZnS}$ ones (Figure $2 \mathrm{H}$ ). Three isoforms of esterase were expressed in pollen grains of which band 2 was very feebly expressed in $\mathrm{ZnD}$ plants. In stigma exudates, expression of esterase isoforms was poor in $\mathrm{ZnD}$ and ZnDF plants and bands 2 and 3 were not expressed in ZnD plants (Figure 2I).

\section{DISCUSSION}

$\mathrm{Zn}$ is an essential micronutrient required for growth and development of plants. Prolonged Zn deficiency produced visible symptoms, checked plants vegetative growth, and reduced reproductive development of plants (Pandey et al., 2006; 2009b). Zn deficiency effects on pollen production, pollen morphology, stigmatic changes, and seed yield suggest a higher requirement of $\mathrm{Zn}$ during the reproductive phase than for the vegetative phase of legume crops. Foliar application of $\mathrm{ZnSO}_{4}$ lead to an increase in concentrations of $\mathrm{Zn}$ in both seed and vegetative part of the plants, which was mainly due to the vital physiological role of $\mathrm{Zn}$ in plant cell (Alloway, 2004). Foliar application of $\mathrm{ZnSO}_{4}$ to $\mathrm{ZnD}$ plants at initiation of flowering minimized the $\mathrm{Zn}$ deficiency effect. However, Zn foliar application to $\mathrm{ZnS}$ plants made little differences to number of flower and seeds suggesting that beyond an optimal requirement, $\mathrm{Zn}$ application does not improve flowering and reproductive yield. 

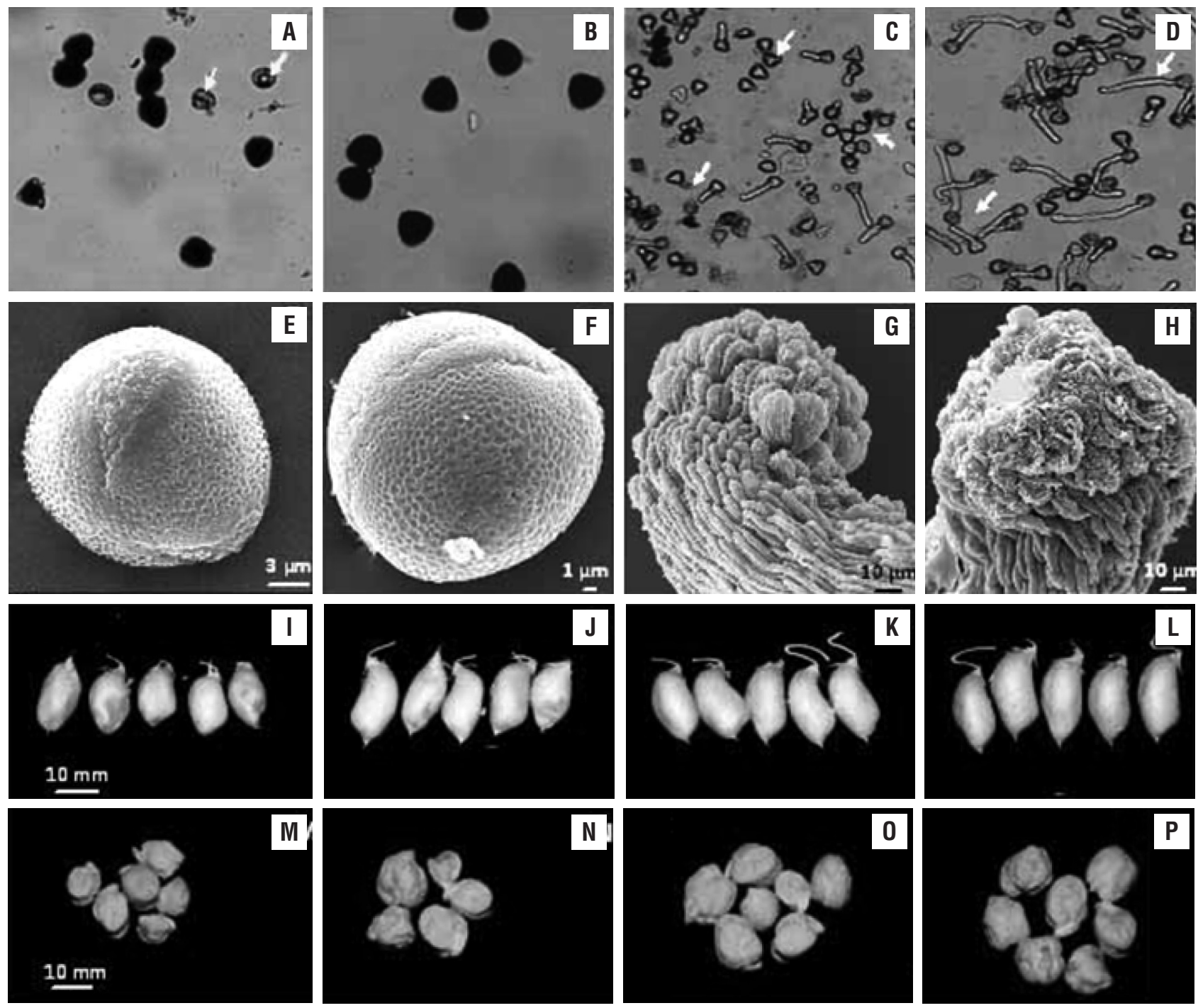

Figure 1. Photographs showing non-viable (arrow) and viable pollen grains of $\mathrm{ZnD}(\mathrm{A})$ and $\mathrm{ZnS}(\mathrm{B})$ plants of chickpea (Cicer arietinum $\mathrm{L}$.). In vitro germination of pollen grains of $\mathrm{ZnD}(\mathrm{C})$, which either fail to germinate or show very small pollen tubes (arrows) as compared to the pollen grains of ZnS (D) plants. Scanning electron microscopy of pollen grains and stigma of $Z n D(E, G)$ and $Z n S$ plants (F, H). Pods $(\mathrm{I}-\mathrm{L})$ and seeds (M-P) of ZnD (I, M), ZnDF (J, N), ZnS (K, O) and ZnSF (L, P) chickpea plants. ZnD: Zn deficient; ZnDF: Zn deficient plants given foliar Zn; ZnS: Zn sufficient; ZnSF: Zn sufficient plants given foliar Zn.

Poor in vitro germination of pollen grains and reduced growth of pollen tube on the stigmatic head resulted in limited fertilization and seed setting in $\mathrm{ZnD}$ chickpea plants. A significant decrease in vitro germination in pollen grains of lentil and black gram suggesting loss of viability due to low $\mathrm{Zn}$ had been reported earlier (Pandey et al., 2006; 2009b). Pandey et al. $(2006 ; 2009 b)$ reported that poor viability of pollen grains of $\mathrm{ZnD}$ plants were due to alterations in the extracellular matrix of the pollen grains, resulting from structural and functional changes during microsporogenesis. The sporollenins synthesized from the tapetum play an important role in the development of the pollen wall. Synthesis of sporollenins involves esterase activity (Nave and Sawhney, 1986), which has been reported to be poorly expressed in $\mathrm{ZnD}$ pollen grains and stigma in the present study. Possibly, some proteins and lipids that play a determining role in pollen hydration and adhesion are regulated by $\mathrm{Zn}$. Poor germination of pollen grains may be due to poor 

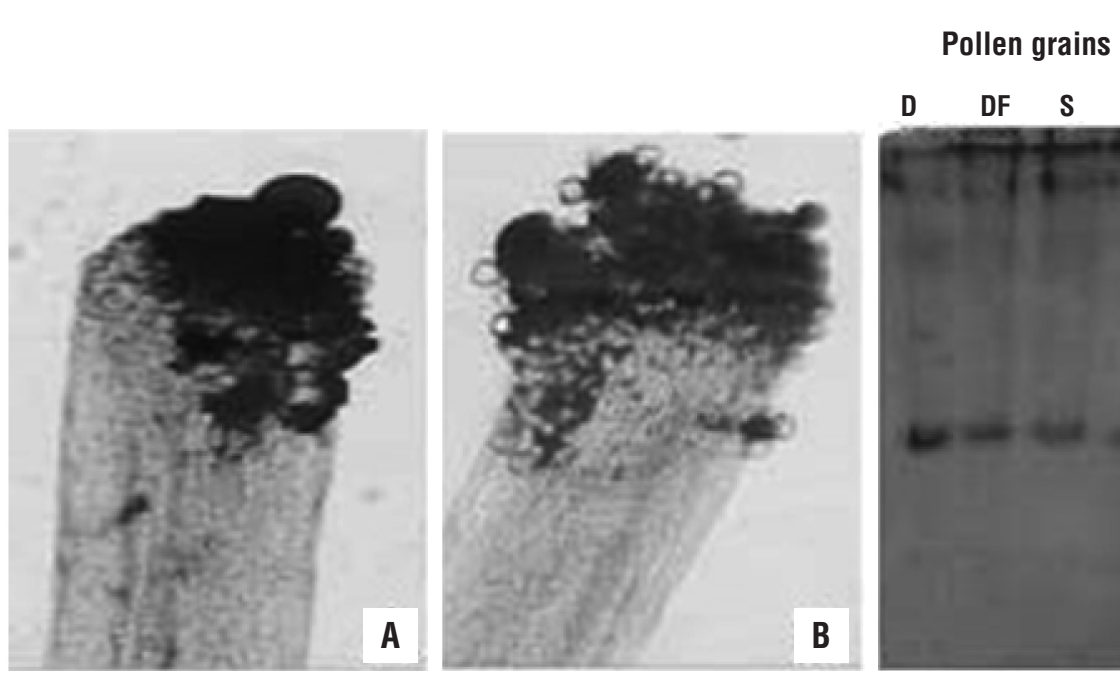

Stigma
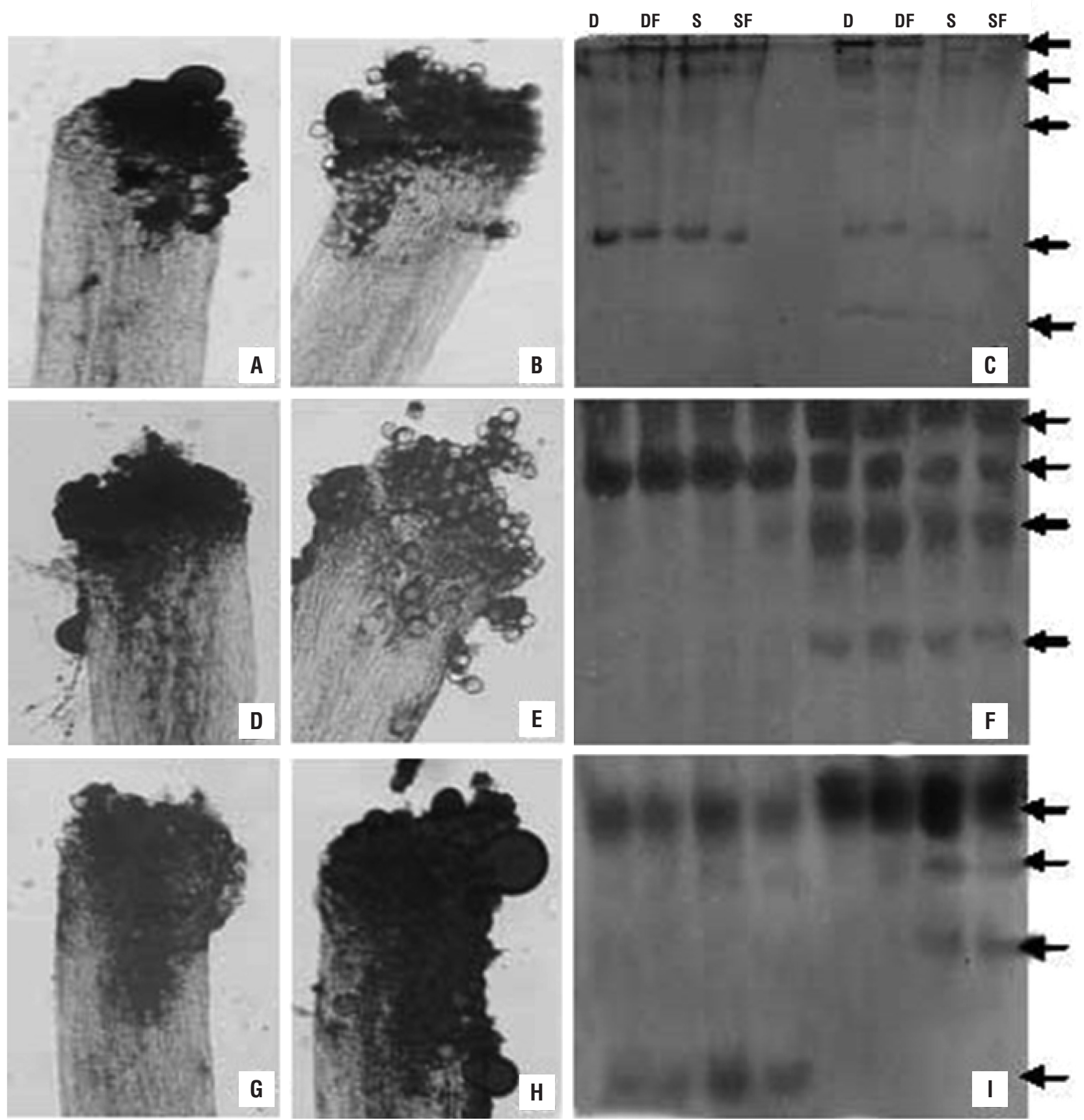

Figure 2. Histochemical localization of peroxidase $(A, B)$, acid phosphatase $(D, E)$, and esterase $(G, H)$ in stigma of $D(A, D, G)$ and $S(B$, $E, H$ ) plants of chickpea (Cicer arietinum L.). Native gels stained for peroxidase (C), acid phosphatase (F) and esterase (I) isoforms in pollen grains and stigma exudates of D, DF, S and SF plants of chickpea. D: Zn deficient; DF: Zn deficient plants given foliar Zn; S: Zn sufficient; SF: Zn sufficient plants given foliar Zn. 
secretion of stigmatic exudates as a consequence of which fewer pollen grains adhere to the stigmas of $\mathrm{ZnD}$ plants, and their germination and pollen tube growth was restricted. It is suggested that the rupture of the stigmatic cuticle is important for pollen and involves the activities of certain enzymes, such as cutinases (Hiscock et al., 1994; Edlund et al., 2004) and esterases (Dafni and Maues, 1998; Hiscock et al., 2002). We found that $\mathrm{Zn}$ deficiency led to increase in activity of acid phosphatase both in stigmatic and pollen extracts. Enhancement of pollen acid phosphatase activity is reported to be inhibitory to pollen tube growth (Roggen and Stanley, 1969). Opposite to the effect on POD and acid phosphatases, esterase was feebly expressed in $\mathrm{ZnD}$ plants. It is likely that observed changes in the activities of stigmatic and pollen esterase and acid phosphatase induced in response to $\mathrm{Zn}$ deficiency stand in way of a favorable pollen-pistil interaction and limit fertilization, providing an explanation to decrease in the number of pods formed.

Zn deficiency also reduced the germinability of seeds (Table 1). Foliar application of $\mathrm{Zn}$ to $\mathrm{ZnD}$ plants at the initiation of flowering partially mitigated the $\mathrm{Zn}$ effects on the seeds and their germinability. These changes are suggestive of a role of $\mathrm{Zn}$ in seed development and maturation. Further work is required to substantiate this. It is however known that the seed development in legumes is controlled by diverse maternal inputs (Weber et al., 2005) and that in Arabidopsis Zn finger transcription factors have a positive influence on seed germination (Liu et al., 2005). In conclusion, Zn Foliar application of $\mathrm{Zn}$ application has a positive effect on plant growth and its reproductive development. Zn deficiency leads to loss of pollen function, impairment in fertilization, and poor development of the seed, which contribute to poor seed yield of legumes grown on low $\mathrm{Zn}$ soils. This can be alleviated through foliar $\mathrm{Zn}$ fertilization of crops at the onset of reproductive phase, especially in $\mathrm{ZnD}$ areas. Foliar fertilization not only enhances productivity, but it is an important strategy for increasing Zn density in seeds improved for human consumption.

\section{ACKNOWLEDGEMENTS}

The author Girish Chandra Pathak is grateful to the Department of Science and Technology, New Delhi, for their financial assistance under Project No. SR/ FT/L-76/2006.

\section{REFERENCES}

Alloway BJ (2004) Zinc in soil and crop nutrition. Areas of the World with Zinc deficiency Problem. Int. Zn Assoc. Publications, Brussels, pp. 1-116.

Brewbaker JL, Kwack BH (1963) The essential role of calcium ion in pollen germination andpollen tube growth. Am. J. Bot. 50:859-865.

Brewbaker JL, Upadhaya MD, Makinen Y, Mac Donald T (1968) Isoenzyne polymorphism in flowering plants. III. Gel Electrophoretic methods and applications. Physiol. Plant. 21:930-940.

Broadly MR, White PJ, Hamnod JP, Zelko I, Lux A (2007) Zinc in plants. New Phytol. 173:677-702.

Cakmak I (2008) Enrichment of cereal grains with zinc: agronomic or genetic biofortification? Plant Soil 302:185-205.

Cakmak I (2010) Enrichment of fertilizers with zinc: An excellent investment for humanity and crop production in India. J. Trace Elem. Med. Biol. 23:281-289.

Dafni A, Maues MM (1998) A rapid and simple procedure to determine stigma receptivity. Sex. Plant Rep. 11:177-180.

Edlund AF, Swanson R, Preuss D (2004) Pollen and stigma structure and function: The role of diversity in pollination. Plant Cell (Suppl.) 16:S84-S97.

Erdtman G (1986) Pollen morphology and plant taxonomy of angiosperms: an introduction to palynology. Leiden, The Netherlands, pp. 6-23.

Grzebisz W, Wronska M, Diatta JB, Dullin P (2008) Effect of Zn foliar application at early stages of maize growth on patterns of nutrients and dry matter accumulation by the canopy. Part I. Zinc uptake patterns and its redistribution among maize organs. J. Elementol. 13:17-28.

Hiscock SJ, Bown D, Gurr SJ, Dickinson HG (2002) Serine esterases are required for pollen tube penetration of the stigma in Brassica. Sex. Plant Rep. 15:65-74.

Hiscock SJ, Dewey FM, Coleman JOD, Dickinson HG (1994) Identification and localization of an active cutinase in the pollen of Brassica napus L. Planta 193:377-384.

Liu PP, Koizuba N, Martin RC, Nonogaki H (2005) The BME3 (Blue Micropylar End 3) GATA zinc finger transcription factor is a positive regulator of Arabidopsis seed germination. Plant J. 44:960-971.

Nave EB, Sawhney VK (1986) Enzymatic changes in post-meiotic anther development in Petunia hybrida. I. Anther ontogeny and isoenzyme analysis. J. Plant Physiol. 125:451-465.

Pandey N, Gupta M, Sharma CP (1995) SEM studies on Zn deficient pollen and Stigma of Vicia faba. Phytomorphology 45:169-173.

Pandey N, Pathak GC, Pandey DK, Pandey R (2009a) Heavy metals, Co, $\mathrm{Ni}, \mathrm{Cu}, \mathrm{Zn}$ and $\mathrm{Cd}$, produce oxidative damage and evoke differential antioxidant responses in spinach. Braz. J. Plant Physiol. 21:103-111.

Pandey N, Pathak GC, Sharma CP (2006) Zinc is critically required for pollen function and fertilization in lentil. J. Trace Elem. Biol. 20:89-96.

Pandey N, Pathak GC, Sharma CP (2009b) Impairment in reproductive development is a major factor limiting seed yield of black gram under zinc deficiency. Biol. Plant. 53:723-727.

Pathak GC, Pandey N (2010) Improving Zn density and seed yield of green gram by foliar application of $\mathrm{Zn}$ at early reproductive phase. Indian J. Plant Physiol. 15:338-342. 
Potarzycki J, Grzebisz W (2009) Effect of Zn foliar application on grain yield of maize and its yielding components. Plant Soil Environ. $55: 519-527$

Raa J (1973) Cytochemical localization of peroxidase in plant cells. Physiol. Plant. 28:32-133.

Roggen HPJR, Stanley RG (1969) Cell-wall-hydrolyzing enzymes in wall formation as measured by pollen tube extension. Planta 84:295-303.
Sharma PN, Chatterjee C, Agarwala SC, Sharma CP (1990) Zinc deficiency and pollen fertility in maize. Plant124:221-225.

Sharma PN, Chatterjee C, Sharma CP, Agarwala SC (1987) Zinc deficiency and anther development in maize. Plant Cell Physiol. 28:11-18.

Shivana KR, Rangaswamy NS (1992) Pollen Biology: A Laboratory Manual. Narosa Publishing House, New Delhi, pp. 45-50.

Weber H, Borisjuk L, Wobus U (2005) Molecular physiology of legume seed development. Annu. Rev. Plant Biol. 56:253-257. 